\title{
Studies on Soil Acrasieae
}

\section{The Active Life of Species of Dictyostelium in Soil and the Influence thereon of Soil Moisture and Bacterial Food}

\author{
BY B. N. SINGH \\ Department of Soil Microbiology, Rothamsted Experimental Station, Harpenden, Herts
}

SUMMARY : When spores of Dictyostelium mucoroides or $D$. giganteum were added to sterilized soil containing a pure culture of an edible bacterium, the resulting myxamoebae actively destroyed the bacteria in the soil. When spores of $D$. mucoroides were added to the centre of a Petri dish of sterilized soil containing bacterial food no fruiting bodies were formed at a moisture content of $15 \%$ or less. At $19 \%$ moisture fruiting bodies were formed at the centre only. At $33 \%$ moisture the central area over which fruiting bodies appeared steadily increased in size until it covered the whole soil surface. Species of Dictyostelium can also pass through the life cycle in fresh unsterilized soil.

The nature of the bacterial food supply affects the growth of species of Dictyostelium in soil as measured by fruiting body formation. Normal fructification occurs on soil containing certain bacterial strains which induce abnormal fructification on agar.

It has been shown (Singh, 1946c, 1947) that species of Dictyostelium are frequently present in arable soils in Great Britain. Their common occurrence in soils of the classical plots at Rothamsted, which have been unmanured or treated only with artificial fertilizers for more than 100 years, suggests that they are true soil inhabitants. The presence of Dictyostelium species in dung which has been lying on the ground for some time indicates that the organisms find suitable bacterial food in these substrates for their development. Among the large variety of bacterial species offered as food to two species of Dictyostelium on non-nutrient agar substrate (Singh, 1947), some were completely eaten, either readily or slowly, whereas others were only partly eaten and the rest were inedible. In soil economy the importance of Acrasieae depends, first, on whether the myxamoebae can lead an active and trophic existence in soil and, secondly, on whether they are present in sufficient numbers to diminish the bacterial population. This paper deals principally with the first question.

\section{EXPERIMENTAL}

Material. Two species, Dictyostelium mucoroides (Brefeld, 1869) and $D$. giganteum (Singh, 1947), were used, which had been isolated from soils and compost heaps by the method of Singh (1947).

Diminution of bacterial numbers by the myxamoebae of

Dictyostelium mucoroides and $\mathrm{D}$. giganteum in sterilized soil

Soil from the plot on Barnfield at Rothamsted, annually manured with 14 tons of farmyard manure per acre, was air dried and passed through a sieve of $3 \mathrm{~mm}$. mesh. It was placed in $300 \mathrm{~g}$. lots in large $7 \cdot 5$ in. diameter Petri 
dishes and autoclaved for $2 \mathrm{hr}$. at $15 \mathrm{lb}$./sq.in. Tests showed that the soil was sterile. The inocula used were: $(a)$ bacteria, $(b)$ bacteria + spores of $D$. mucoroides, (c) bacteria + spores of $\boldsymbol{D}$. giganteum.

A common soil bacterium (strain 4002) which is readily and completely eaten by the myxamoebae and on which normal fruiting bodies of Dictyostelium spp). are produced, was selected for this experiment. One or two loopfuls of a 2-3-day culture of bacterium 4002 on nutrient agar were spread in a thin layer on non-nutrient agar (1.5\% agar in $0.5 \% \mathrm{NaCl}$; $\mathrm{pH} \mathrm{6.5-6.8)} \mathrm{in} \mathrm{Petri} \mathrm{dishes.}$ A spore mass, or sorus, raised well above the surface of its culture medium, was gently punctured by a fine sterilized needle and the spores added to the bacterial culture on the non-nutrient agar. When fruiting bodies were formed, within 3-4 days, the spores were inoculated on to freshly prepared bacterial cultures. This process was repeated until cultures of $D$. mucoroides and $D$. giganteum growing on pure cultures of bacterium 4002 were obtained. For inoculation of the soil plates, growth from 2-3-day cultures of bacterium 4002 on nutrient agar slopes was gently scraped off, suspended in $0.5 \% \mathrm{NaCl}$ and the number of bacteria $/ \mathrm{ml}$. determined by a haemocytometer count. Approximately the same number of bacteria was inoculated into each of the soil samples contained in the large Petri dishes. During inoculation the soils were shaken to distribute the bacteria as uniformly as possible. Large numbers of spores of $D$. mucoroides and $D$. giganteum produced on bacterium 4002 were then suspended in $0.5 \% \mathrm{NaCl}$ and the number $/ \mathrm{ml}$. determined in a haemocytometer. Approximately the same number of spores, $64,000 / \mathrm{g}$. soil, was added to each soil. The moisture content of the soils was brought to $33 \%$ (on dry-weight basis) by adding sterilized tap water. Immediately after the double inoculation counts of the bacteria were made by plating from each of the soils. The number of viable bacteria contained in each soil sample was approximately the same. The soils were then incubated at $19-20^{\circ}$.

The counts of viable bacteria were made at intervals. From each Petri dish ten random samples were taken by means of a sterilized cork borer; they were thoroughly mixed and $10 \mathrm{~g}$. of the mixture used to make the necessary dilutions. The results are shown in Fig. 1. In the control soil the highest bacterial count was obtained in 10 days. Over the whole period of the experiment the rise in bacterial numbers was much smaller in the soils inoculated with Dictyostelium spp. It was most marked in the first sample, after 3 days' incubation. This was probably due to the fact that after the myxamoebae emerged from the spores, they multiplied rapidly for a few days before giving pseudoplasmodia and fruiting bodies. It is during this intensive reproduction stage that large numbers of bacteria are consumed by the myxamoebac. Once the latter begin to aggregate to pseudoplasmodia, the myxamoebae cease feeding. Within 3-5 days fruiting bodies were seen over the soil surface in large numbers. It is thus natural that when most of the myxamoebae have given rise to pseudoplasmodia the consumption of bacteria should be much diminished.

The destruction of bacteria by $D$. mucoroides, isolated from soil, was more marked than that by $D$. giganteum, which was isolated from an actively decomposing compost heap of straw and sludge. 
The spread of myxamoebae of Dictyostelium in sterilized soil and the formation of fruiting bodies at different moisture contents

Myxamoebae of Dictyostelium are able to feed upon dead bacteria and possibly also upon dead cells of other micro-organisms present in the sterilized soil. When the spores or myxamoebae were inoculated into sterilized soil to which no viable bacteria had been added, some fruiting bodies were formed in soil at moisture contents between 20 and $40 \%$. The formation of fruiting bodies at different moisture contents of the soil is described below.

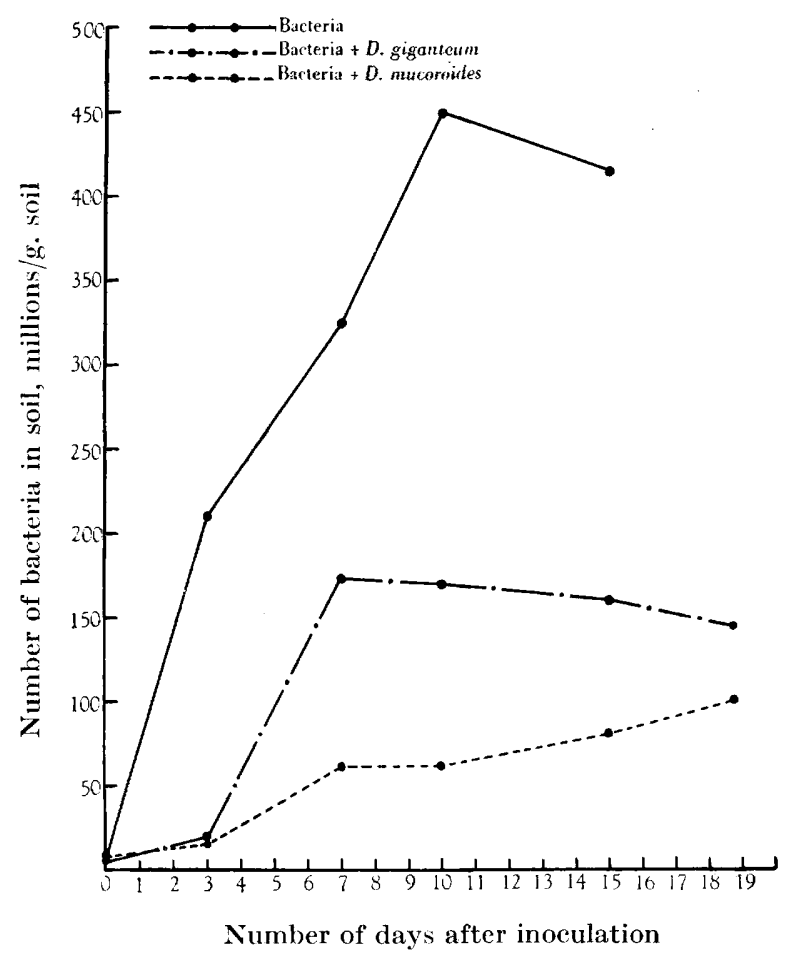

Fig. 1. The growth of bacterium 4002 in sterilized soil, alone and in the presence of Dictyostelium spp.

Two hundred and fifty g. portions of air-dried sifted soil were put into large Petri dishes $(7 \cdot 6 \mathrm{in}$. diameter) and sterilized. Their moisture contents were adjusted roughly to $8,10,15,19,25$ and $33 \%$ by dry weight, and a young culture of bacterium 4002 suspended in $0.5 \% \mathrm{NaCl}$ added. Approximately the same number of bacteria/g. soil was inoculated into each of the soils. A cylinder of soil $(0 \cdot 5 \mathrm{in}$. diameter) was removed from the centre of each Petri dish by a cork-borer, and the space thus made was filled with air-dried and sterilized soil. Upon this was placed one drop of a thick suspension of spores of $\boldsymbol{D}$. mucoroides in $\mathbf{0 . 5} \% \mathrm{NaCl}$. The small amount of dry soil absorbed the drop of water and thus prevented a local accumulation of moisture which might have led to the water currents carrying the spores outwards. Lids of small 1 in. 
Petri dishes were placed on the top of this soil over the site of the Dictyostelium seeding to stop the spread through the air of spores from fruiting bodies produced at the centre. The plates were incubated at 20-21 . Observations on the development of fruiting bodies on the soil surface are recorded in Table 1.

Table 1. The approximately circular area occupied by fruiting bodies when spores of Dictyostelium mucoroides were inoculated centrally in $7 \cdot 5$ in. Petri dishes of sterilized soil of different moisture content

\begin{tabular}{|c|c|c|c|c|c|c|}
\hline \multirow{3}{*}{$\begin{array}{c}\text { Moisture } \\
\text { content of } \\
\text { soil }(\%)\end{array}$} & \multicolumn{6}{|c|}{ Days after inoculation } \\
\hline & 3 & 4 & 5 & 6 & 8 & 13 \\
\hline & \multicolumn{6}{|c|}{ Area occupied by fruiting bodies (sq.in.) } \\
\hline 8 & 0 & - & - & - & - & 0 \\
\hline 10 & 0 & - & - & - & - & 0 \\
\hline 15 & 0 & - & - & $\ldots$ & - & 0 \\
\hline 19 & 0 & - & - & - & $0 \cdot 3$ & $0 \cdot 3$ \\
\hline 25 & 0 & - & - & $0 \cdot 5$ & - & $3 \cdot 1$ \\
\hline 33 & $0 \cdot 8$ & $3 \cdot 1$ & $12 \cdot 5$ & $28 \cdot 3$ & 一 & 176 \\
\hline
\end{tabular}

No fruiting bodies were formed in 13 days in soils with 8,10 and $15 \%$ moisture; at $19 \%$ moisture some were formed on the 8 th day at the place of inoculation, but they remained confined to a small area in the centre of the Petri dish. Fruiting bodies were produced on the 6 th day at $25 \%$ moisture and were visible up to a distance of an inch from the site of inoculation on the 13th day. At $33 \%$ moisture, fruiting bodies were formed within about $\frac{1}{2}$ in. of the centre of the Petri dish on the 3rd day, and thereafter the area over which they appeared increased steadily until it covered the Petri dish after 7 days. On the 8th day large numbers of fruiting bodies were seen over the whole soil surface. It is interesting to note that by increasing the moisture content of the soil the fruiting bodies not only appeared much earlier but their spread was also much quicker. This suggests that spreading of these Dictyostelium spp. is due to migration of myxamoebae through the soil moisture. On the 4th day of the growth at $33 \%$ moisture fruiting bodies were seen inside the area enclosed by the lid of the small Petri dish, as well as outside it. It seems probable that in nature Acrasieae spread both by the dispersal of the spores and by the migration of the myxamoebae. When the soils of lower moisture content, in which no fruiting bodies had been formed, were brought to $35-40 \%$ moisture, large numbers of fruiting bodies were formed throughout the soil within 7-10 days. The spread of fruiting bodies and their formation was unchanged when the moisture content was raised from 33 to $40 \%$. It is interesting that no fruiting bodies were seen, even at the centre, on soil with less than $15 \%$ moisture. It appears that a certain amount of moisture is necessary for the germination of the spores or for the aggregation of the myxamoebae to form pseudoplasmodia.

In the next experiment the myxamoebae of $D$. mucoroides were substituted for the spores and a drop of a thick suspension of the myxamoebae in $\mathbf{0 . 5} \%$ $\mathrm{NaCl}$ was inoculated in the centre of the Petri dish (Table 2). At $10 \%$ moisture no fruiting bodies were formed; at $15 \%$ a few were seen at the place of inocula- 
tion on the 3rd day, remaining confined to a small area up to 19 days. At $20 \%$ moisture fruiting bodies appeared on the 3rd day, as with $15 \%$ moisture, but they spread $\frac{1}{2}$ in. within 19 days. The appearance of the fruiting bodies at $\mathbf{2 5}$ and $30 \%$ moisture took place on the 3rd day, but their spread was much more rapid at $30 \%$ than at $25 \%$ moisture. At $30 \%$ moisture fruiting bodies were seen throughout the soil surface within 10-12 days. When myxamoebae were inoculated into soil the fruiting bodies appeared a few days earlier at 20 and

Table 2. The approximately circular area occupied by fruiting bodies when myxamoebae of Dictyostelium mucoroides were inoculated centrally in $\mathbf{7 \cdot 5}$ in. Petri dishes of sterilized soil of different moisture content

Days after inoculation

\begin{tabular}{cccccc}
$\begin{array}{c}\text { Moisture } \\
\text { content of } \\
\text { soil }(\%)\end{array}$ & 2 & $\begin{array}{c}3 \\
\text { Area occupied by fruiting bodies (sq.in.) }\end{array}$ \\
\cline { 2 - 4 } 10 & 0 & - & - & - & 0 \\
15 & 0 & $0 \cdot 3$ & $0 \cdot 5$ & - & $0 \cdot 5$ \\
20 & 0 & $0 \cdot 3$ & - & - & $0 \cdot 8$ \\
25 & 0 & $0 \cdot 5$ & - & $0 \cdot 8$ & $3 \cdot 1$ \\
30 & 0 & $0 \cdot 5$ & - & - & 176
\end{tabular}

$\mathbf{2 5} \%$ moisture than they did when spores were used as inoculum. This suggests that at these moisture levels it takes some time for the spores to germinate and give rise to myxamoebae. At $33 \%$ moisture, however, fruiting bodies made their appearance on the 3rd day when either spores or myxamoebae were used as inoculum. It seems that this higher moisture content is required for the rapid germination of the spores to give rise to myxamoebae. The soil of $10 \%$ moisture, where no fruiting bodies had been formed, was brought to $40 \%$ moisture at the end of $\mathbf{1 7}$ days; large numbers of fruiting bodies were then formed throughout the soil within the next 8-10 days.

\section{Inoculation of spores and myxamoebae into natural soil}

Rothamsted Barnfield farmyard manured soil was air dried and passed through a sieve of $3 \mathrm{~mm}$. mesh. Fifty g. portions of this soil were put in each Petri dish. Some of these dishes were inoculated with a thick suspension of the spores, some with the myxamoebae of $\boldsymbol{D}$. mucoroides while the others were left as control. The moisture content of the soils ranged between 30 and $40 \%$. The plates were incubated at $20-21^{\circ}$. Within $\gamma-\mathbf{1 5}$ days a few fruiting bodies were formed in some of the soils which received spores or myxamoebae, but no fruiting bodies could be seen in the control soil.

Kubiena and his colleagues (see Kubiena, 1938) in their extensive studies in micropedology by direct observation of various soils have given excellent photographs of stalks and sori which from their appearance are almost certainly those of species of Dictyostelium, although they identified them as the fruiting bodies of fungi. The identification of these bodies as Acrasieae is supported by the fact that they could not grow them on media suitable for fungi even after repeated trials (cf. PI. 1 with the photographs of Kubiena, 1938). 
Production of fruiting bodies of Dictyostelium mucoroides in sterilized
soil with the addition of different bacterial strains

Forty g. portions of Rothamsted Barnfield farmyard manured soil were put into Petri dishes, sterilized, and each inoculated with approximately the same number of bacteria from 2- to 3-day nutrient agar cultures of five strains of common (4000,4002,4003, 4022 and 4039) and four strains of rare $(2881 \mathrm{C}$, 2650,4087 and 6699 ) soil bacteria. The inoculum of the spores of $D$. mucoroides was approximately $20,000 / \mathrm{g}$. soil. A few dishes were inoculated with the spores only. The methods used were those described above. The moisture content of the soil was $33 \%$ after sterilization; the plates were incubated at $20-21^{\circ}$. The common and rare strains of bacteria selected were known to multiply well and

Table 3. The production of fruiting bodies $(F B)$ of Dictyostelium mucoroides on sterile soil or non-nutrient agar in presence of different strains of bacteria

The different strains of bacteria were inoculated into sterilized soil or spread over the nonnutrient agar, and spores of $\boldsymbol{D}$. mucoroides added.

$\begin{array}{cccc}\begin{array}{c}\text { Identification } \\ \text { nos. of bacterial } \\ \text { strains used }\end{array} & \begin{array}{c}\text { Sterilized soil } \\ \text { Relative numbers of } \\ \text { fruiting bodies formed }\end{array} & \begin{array}{c}\text { Characters } \\ \text { of fruiting bodies }\end{array} & \begin{array}{c}\text { Edibility of bacteria } \\ \text { by the myxamoebae }\end{array} \\ 4000 & \text { Large } & \text { Normal } & \text { Complete } \\ 4002 & \text { Large } & \text { Normal } & \text { Complete } \\ 4003 & \text { Large } & \text { Normal } & \text { Complete } \\ 4022 & \text { Very small } & \text { Normal } & \text { Partial } \\ 2881 \mathrm{C} & \text { Very small } & \text { Abnormal } & \text { Partial } \\ 4087 & \text { Very small } & \text { Abnormal } & \text { Complete } \\ 4039 & \text { Large } & \text { Abnormal } & \text { Partial } \\ 2650 & \text { Large } & \text { Abnormal } & \text { Complete } \\ 6699 & \text { Large } & \text { Abnormal } & \text { Partial } \\ \text { Control } & \text { Very small } & - & -\end{array}$

attain high numbers in sterilized soil. A rough quantitative estimation of the fruiting bodies was made at the end of 10 days (Table 3 ). Some fruiting bodies were produced from the spores of $\boldsymbol{D}$. mucoroides in the absence of the added bacteria. Large numbers were produced on six of the bacterial strains; and on the other three and in the control soil only very few. Thus the quality of the bacterial flora affected the development of the Dictyostelium spp. in soil as reflected in the number of fruiting bodies produced. The effect of these bacterial strains on the fruiting of these species of Dictyostelium on non-nutrient agar has already been described (Singh, 1947). Strains 4000, 4002 and 4003 were completely consumed by the myxamoebae on non-nutrient agar and induced abundant and normal fruiting. They also induced numerous fruiting bodies in soil. Strain 4022 was only partly eaten on agar though it induced normal fruiting bodies; it induced very little fruiting in soil. Strains $2881 \mathrm{C}$ and 4087 induced abnormal fruiting on agar and very few fruiting bodies in soil. But strains 4039, 2650 and 6699 although they induced abnormal fruiting on agar yet enabled large numbers of normal fruiting bodies to be produced in soil. 
Journal of General Microbiology, Vol. 1, No. 3

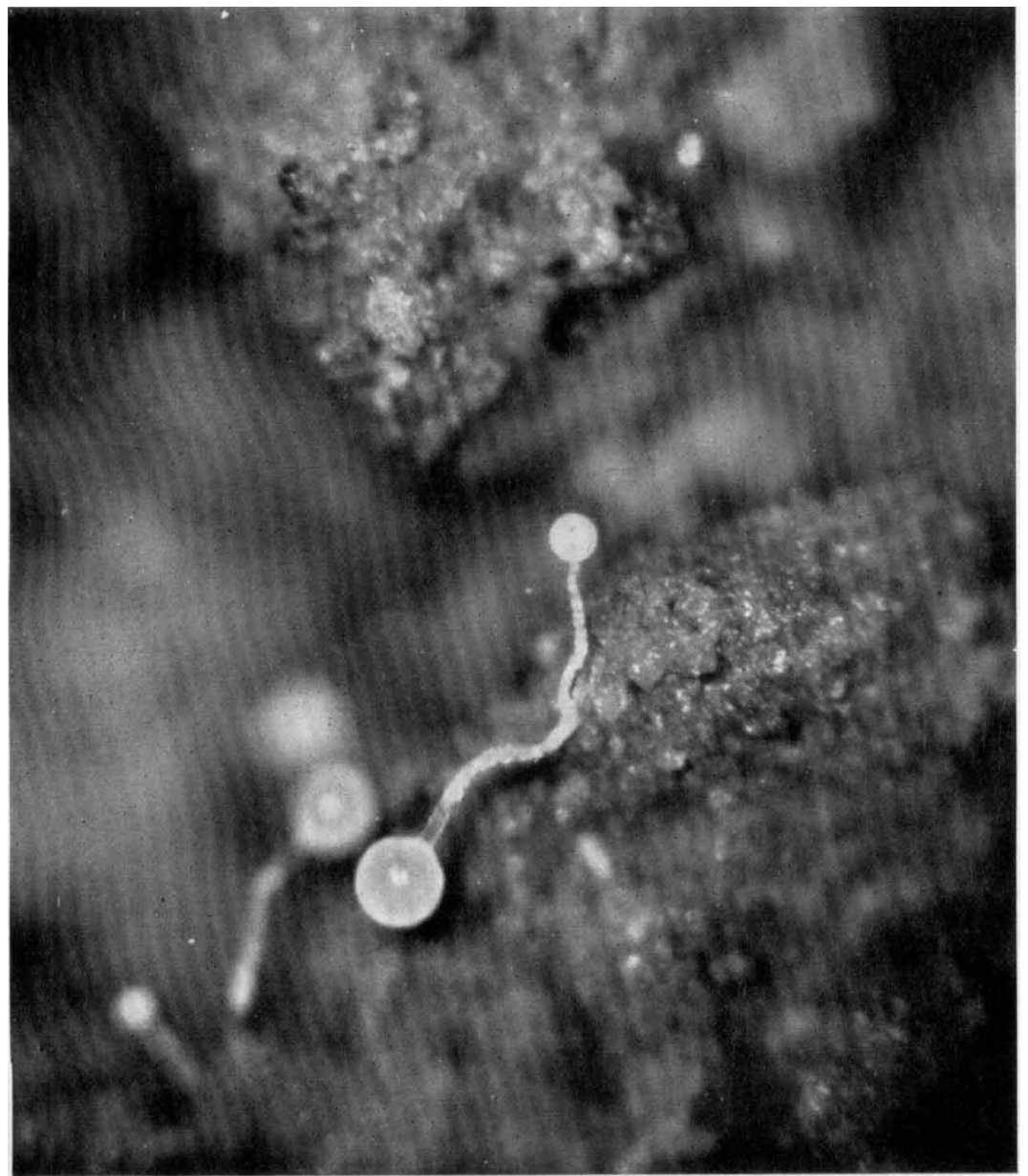

Fruiting bodies of Dictyostelium mucoroides growing in sterilized soil inoculated with soil bacterium $4002(\times 20)$.

B. N. Singh-Studies on soll acrasieae. Plate 1 



\section{DISCUSSION}

These results show that the myxamoebae of Dictyostelium mucoroides and $D$. giganteum are able to multiply and produce pseudoplasmodia and fruiting bodies in soil, whether sterilized or not, containing a suitable bacterial food supply. They also show that for certain strains of bacteria, differential feeding effects occur in soil as well as on agar. 'The direct evidence that the amoebae of the Acrasieae lead an active life in soil lends support to the indirect evidence derived from dilution counts that the true amoebae are also active inhabitants, since the two types of amoebae are identical in their feeding habit and general mode of life.

It is interesting that the rate of migration of the myxamoebae through soil as estimated from the increasing area over which fruiting bodies appeared was approximately I in. $\mathbf{2 4} \mathrm{hr}$. at suitable water contents. This corresponds well with that found by Thornton \& Gangulee (1926) for the spread of Rhizobium spp. in sterilized soil.

This work was made possible by a grant from the Agricultural Research Council, to whom the author's thanks are due. It is a pleasure to express my sincere thanks to Dr H. G. Thornton, F.R.S., and Miss L. M. Crump for their interest in this work.

\section{REFERENCES}

Brefeld, O. (1869). Dictyostelium mucoroides. Ein neuer Organismus aus der Verwandschaft der Myxomyceten. Abh. Senckenb. naturf. Ges. 7, 85.

Kubiena, W. L. (1938). Micropedology. Ames, Iowa: Collegiate Press, Inc.

Singh, B. N. (1946a). A method of estimating the number of soil Protozoa, especially amoebae, based on their differential feeding on bacteria by Protozoa. Ann. appl. Biol. 33, 112.

Singh, B. N. (1946b). Silica jelly as a substrate for counting holozoic Protozoa. Nature, Lond., 157, 302.

Singh, B. N. $(1946 c)$. Soil Acrasieae and their bacterial food supply. Nature, Lond., $157,133$.

Singh, B. N. (1947). Studies on soil Acrasieae. 1. Distribution of species of Dictyostelium in soils of Great Britain and the effect of bacteria on their development. J. gen. Microbiol. 1, 11.

Thornton, H. G. \& Gangulee, N. (1926). The life-cycle of the nodule organism, Bacillus radicicola (Beij.), in soil and its relation to the infection of the host plant. Proc. Roy. Soc. B, 99, 427.

(Received 24 February 1947) 